\title{
Investigation of the reasons of negative perceptions of undergraduate students regarding the modern physics course
}

\author{
Ayhan Aksakalli1, Riza Salar1,* and Umit Turgut ${ }^{1}$ \\ ${ }^{1}$ Kazim Karabekir Faculty of Education, Ataturk University, Erzurum, Turkey \\ For correspondence: rizasalar@atauni.edu.tr
}

\begin{abstract}
In this research, the negative perceptions of undergraduate students regarding modern physics course and the causes of their negative perceptions have been investigated. For this investigation, a qualitative and quantitative method (mix method) was chosen for data collection and analysis. The study group of the research consists of a total of 169 (21-25 years old) undergraduate students studying at a state university in Turkey. Focus group interview, repertory grid technique and individual interview were used for gathering data. According to results, seven negative perceptions were determined regarding the modern physics course and four main themes were specified the causes of negative perceptions of students related to modern physics.
\end{abstract}

Keywords: modern physics, negative perceptions, physics education, repertory grid

\section{Introduction}

Physics is a branch of a particular discipline trying to explain everything about nature from micro to macro, living to nonliving with the help of mathematical contents, theories and rules (Hallaun \& Hestenes, 1985a). Many students have various problems related to physics course and they consider physics as it consists of the facts and phenomena. They don't use physics in their daily lives; and additionally, they are not able to solve problems regarding this course. However, the students dealing with these problems think that they have been very successful during their whole physics education, which is an ironic situation (Prosser, Walker \& Millar, 1996).

In the early 1980s, Trowbridge and McDermott (1980), Viennot and Rozier (1994) and some other researchers (Hallaun \& Hestenes, 1985b; Clement, 1982) have determined that the students come to physics class with some prior knowledge and intuitions. They have considered this prior knowledge related to the course as an outcome of the experiences that students had in their daily lives, and they have suggested that these experiences have caused some misconceptions, creation of a number of alternative concepts and some prior information that can be considered scientifically incorrect.

Modern physics is one of the many sub-fields in physics. Modern physics is the basis of solid state physics, nuclear physics, theory of laser, molecular physics, and all the practical uses presented in the light of these science fields. However, it has never been fully understood and not explained at all; therefore, never been a popular field even it has deserved. Niels Bohr has said that "Anyone not shocked by quantum mechanics has not yet understood it" related to quantum physics, which is one of the most important cornerstones of modern physics, and similarly, Heisenberg said that "I repeated to myself again and again the question: Can nature possibly be as absurd as it seemed to us in these atomic experiments?". These sayings present how the phenomenon related to modern physics contradict with our common sense.

If we consider that the observation of events in modern physics appear as a possibility, we can suggest that the modern physics theory has brought a new perspective to the concept certainty and 
absolutism by questioning the approach of "determinism", which has been a dominant approach for centuries. As a result of this, it has led classical physics predictions and precursors to be questioned again by causing "interpretive paradigm" to take place in the science books again. Modern physics tells us to give up asking the same questions in order to understand the nature. According to this situation, more importance should be given to the education and training of modern physics concepts and their philosophical interpretation at the universities to understand the nature; because modern physics, which is comprehensive and so important, is more difficult than classical physics. It is quite difficult to understand due to its abstract and difficult structure. According to a study conducted by McDermott (1991) and Redish \& Steinberg (1999), the conceptual content of modern physics is less understood than expected by the students.

Many problems are experienced during the education of modern physics. The main ones can be listed as follows (Ozcan, 2011):

1. Students fail in mathematical solutions, because they cannot stimulate the necessary concepts of modern physics in their minds.

2. The negative concept images of the students regarding modern physics make this course less important from their point of view.

3. The traditional teaching method of this course makes it more difficult to understand as needed.

4. Students are not able to adopt the concepts of modern physics sufficiently due to the failure to establish the connection between modern physics and daily life.

5. The knowledge of the students regarding classical physics is an obstacle against learning the concepts of modern physics. Because they don't know the difference between classical physics and modern physics very well.

6. The preconceived approach of the students to modern physics concepts causes confusion in the minds and results in failure in this course.

7. Since the instructors of the course don't know the extent of negative conceptual images of the students regarding modern physics, they may apply non-scientific ways of simplifications during presentation of the course. In this case, the compelling factors encourage students to learn disappear and the conceptual background of the course cannot be created.

As mentioned above, one of the reasons cause students to fail in the modern physics course is their preconceptions. Students may have negative perceptions related to modern physics. These negative perceptions are dragging the students to failure. Thus, it is important to identify the negative perceptions and present the causes of these perceptions. In this study, it has been aimed to identify the negative perceptions of undergraduate students regarding modern physics course and find the causes of their negative perceptions.

\section{Method}

This study is a combination of quantitative and qualitative research methods. The "recursive analysis" was used throughout the research and the data collection has been made by considering this analysis method (McMillan \& Schumacher, 2010). In addition, different data collection methods were also used when they are needed during the study and the credibility of the results of the study is increased. The study was conducted with undergraduate students who are taking physics course. First, focus group interview was conducted with 36 students. Then repertory grid was applied to 123 students. Finally, 10 students were interviewed in person.

Participants. The study group of the research consists of a total of 169 (21-25 years old) undergraduate students studying at a state university in Turkey. The students are currently taking physics course and they have already completed the modern physics, quantum physics and quantum mechanics courses successfully. 


\section{Data Collection}

In this study, focus group interviews, the repertory grid technique (RGT) and the semi-structured interview form developed according to the RGT analysis were used as the data collection tools. The repertory grid was created by using the data obtained from the focus group interview. RGT was also used in the determination of the students to be interviewed.

Focus group interview. Focus group interview is a special group interview technique structured in order to determine the knowledge and ideas of a selected group of participants in detail in the framework of a specific topic. The most convenient number of the participants is 10-12. The interview is managed by an expert by using the asking questions and summarizing techniques to present the thoughts and experiences of the people.

In this study, each focus group interview was conducted with 12 people and each one has lasted approximately 50 minutes. Interviews were completed with three different groups. In the interviews, some key sentences regarding modern physics were given to the students and their most repeated negative perceptions towards modern physics and its contents have been identified by using the negative perceptions previously presented by the researchers.

Repertory grid technique. Personal construct psychology (PCP) was founded in 1950s by George A. Kelly. This personality is a model emerged from the interaction of a person with other people and events around him/her. In PCP, each individual develops his/her own conceptual scheme or system and these are expressed as a unique system of bipolar dimensions known as the individual structure. According to $\mathrm{PCP}$, "A person looks from the transparent partners and templates that have been created in his/her world and try to adapt to the reality that the world consists of" (Kelly, 1955). Individuals do not enter into new areas as a blank page; contrarily, they bring their methods of observations to the world and the "constructs" they have used before along. Kelly suggests that a certain number of "constructs" can be reached through the assessment of events building everyone's world. The events can be called as "elements". In addition, it has been argued that the construct of each individual can be considered as bipolar. This can be defined as polar adjectives or phrases and refers to the "dimensions or axes concerned" used to separate elements by individuals. The construct can be thought as an estimate made in advance to present the world of a student. The basis of this technique is creating constructs used to expand the meaning into a set of elements and then leading the subject to rate these elements in accordance with the constructs created. Elements that make up the repertory grid can be individuals, organizations, objects, thoughts and events. Elements are generally determined according to the topic studied by the researcher. Elements can also be determined by the researcher and participant together. The constructs refer to the similarity, opposition and relationship between elements and they are in a pole structure. There are many ways to determine the constructs. In general, they are determined by the researcher and the person who is interviewed. Elements are used while determining the constructs. The researcher asks the similarities and different aspects of the elements to the participants as groups of two. He/she reaches the constructs through the responses. Or the researcher asks the participant to group two of three elements that he/she has selected. The researcher asks the participant to see how he/she made this grouping and reaches the constructs through responses of the participant. Constructs can also be determined by the researcher. However, this may cause the grid to not to be flexible. An example of repertory grid is given in Figure 1. 


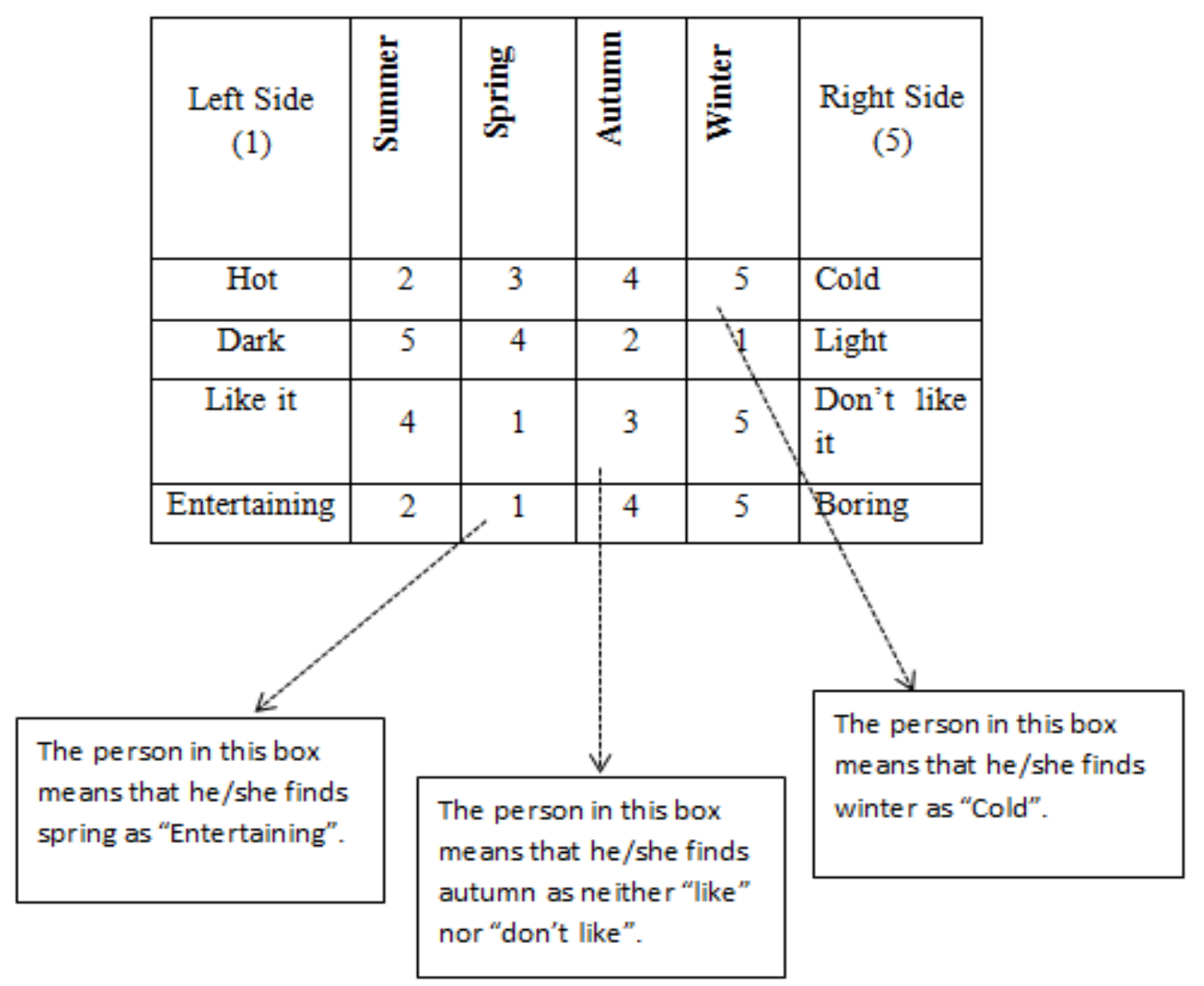

Figure 1. Sample Repertory Grid

In this study, a repertory grid consisting of 22 elements and 8 constructs contains the concepts of modern physics has been prepared in order to recognize students' negative perceptions towards the concepts of modern physics. The elements in the grid have been selected after reviewing the content of modern physics course taught in faculty and the constructs have been selected as a result of evaluating the results of focus group interviews.

The repertory grid is a matrix consisting of a total of 22 elements and 8 constructs. While the "elements" are representing the topics taught in physics class, the "constructs" represents the negative perceptions of the students towards modern physics. One of the constructs presents the positive perceptions while the remaining 7 present the negative ones. The focus group interviews held with the students were effective on the formation of these negative perceptions.

Individual interviews. The individual interviews are the semi-structured interviews conducted with students who have received higher negative perception scores from the repertory grid that was prepared in order to identify the negative perception of the concepts of the students towards modern physics concepts. According to results obtained from the repertory grid, the criterion based sampling method, one of the purposeful sampling methods, was used in the qualitative research to select the students for individual interviews (Patton, 2005). The purposeful sampling method allows the situations, which are considered as having a wealth of information, to be studied in detail. Basic understanding of the extent of the criterion based sampling method is studying all the cases that meet a set of predetermined criteria. The criteria or criterion can be created by the researcher or the list of criteria previously prepared can be used (Patton, 2005).

In this study, the main criterion in the selection of students to do individual interviews is the students with higher negative perception scores received from RGT. All individual interviews were carried out with the voluntary participation of students with higher negative perception scores. The interviews 
were conducted with a total of ten participants in person. Each interview was lasted about 60 minutes. The participants were informed in advance that the interviews would be recorded. During the interviews, every convenience is provided for the students to express their thoughts more freely. A detailed review of the literature regarding modern physics and its content was performed by the researcher before preparing the interview form (Akarsu, 2011; Bilal \& Erol, 2007; Selcuk, Caliskan \& Ajangiz, 2009; Euler, Hanselmann, Müller, \& Zollman, 1999; Mannila, Koponen \& Niskanen, 2002; Turgut, Gurbuz, Salar \& Toman, 2013). As a result of the literature review, the problems experienced in modern physics and its contents have been listed under four main themes (category). A 28question interview form was prepared by the researcher based on these four themes. The form was controlled by two professors and two Turkish teachers before implementing it to the students for having a consensus towards true meaning of the constructs representing words, sentences and negative perceptions. In addition, a pilot study was conducted before implementing the 28-question interview form. The validation and reliability of the study and whether the questions are in accordance with the goals of the study have been checked by the same expert group based on the pilot study conducted. Some of the questions were updated and applied to the participants by taking the feedbacks into account received from the experts. The data collection phase has been started after considering that the interview questions have provided the data needed. Additional questions were developed at the end of the study to make the questions more understandable in the interview form. Thus, it has been easier for participants to understand the questions.

As a result of reviewing the literature, the themes (categories) created by the researcher towards the causes of negative perceptions of students related to modern physics and its contents are as follows:

$\begin{array}{ll}\text { - } & \text { The effect of instructors } \\ \text { - } & \text { The effect of in class activities } \\ \text { - } & \text { The effect of curriculum } \\ \text { - } & \text { The effect of textbooks }\end{array}$

\section{Data Analysis}

In this study, the data analysis consists of five stages. In the first stage, the repetition numbers of the most commonly used constructs were identified by analyzing the focus group interview from developed. In the second stage, the density distribution of negative perceptions of the participants have been identified by calculating the percentage values in the RGT constructs using SPSS 17 package software. In the third stage, the basis for the students who will be interviewed has been prepared by calculating the negative perception scores of each participant and collecting all the values given to the negative perceptions. In the fourth stage, the descriptive analysis has been employed in order to answer the question of "what"; in other words, to present what results the data obtained from the individual interviews point out regarding the research problem (Patton, 2005). In the fifth stage, the content analysis method was used. The content analysis is defined as a systematic and repeatable technique, in which some words of a text can be summarized by using content categories with some coding based on certain rules (Patton, 2005). The categories were identified by coding the raw data from interviews. Data has become meaningful for the reader by classifying them under these categories. The coding and categorization process was conducted by the researcher repeatedly. Thus, unnecessary coding have been removed and new coding have been added to necessary sections by adhering to the purpose and problem of the research.

\section{Findings}

The Findings Obtained from Focus Group Interviews. The focus group interviews were conducted with three different groups consisting of 12 people. In the interviews, the most common negative perceptions of the students and their frequencies have been identified. The most repeated negative perceptions of the students regarding modern physics and its contents during the interviews are given in Table 1. 
Table 1. The most repeated negative perceptions of the students regarding modern physics and its contents during the interviews

\begin{tabular}{ll}
\hline $\begin{array}{l}\text { The Key Constructs Used in the Interviews } \\
\text { (Number of the Students) }\end{array}$ & $\begin{array}{l}\text { Most Repeated Constructs During the } \\
\text { Interviews }\end{array}$ \\
\hline Concerns (6) & 12 \\
\hline Abstract (5) & 9 \\
\hline Preconception (5) & 7 \\
\hline Alienation (8) & 13 \\
\hline Contains Conceptual Difficulty (3) & 6 \\
\hline Includes Mathematical Challenge (4) & 6 \\
\hline It is Difficult to Visualize (5) & 10 \\
\hline
\end{tabular}

The most repeated seven negative perceptions in the focus group interviews constitute the constructs in the repertory grid. These researchers have added the "interesting" construct to these constructs. Thus, a total of 8 constructs took place in the repertory grid.

The Findings Obtained from the Repertory Grid Technique. The percentage values given to the constructs in the repertory grid, which was applied in a total of 123 participants, were calculated using SPSS 17 computer program. Since the negative perceptions of the students were aimed to be identified, only the pole pointing to the negative perception has been taken into account from the bipolar grid. In the scoring grid handed over to the students, the left side was negative and the students who have given either 1 or 2 points to this side were considered as those that have a negative perception. Thus, the percentage values of the students who have given either 1 or 2 points were gathered and given in Table 2.

Table 2. The Percentage Analysis of Repertory Grid

\begin{tabular}{|c|c|c|c|c|c|c|c|c|c|c|c|c|c|c|c|c|c|c|c|c|c|c|}
\hline & 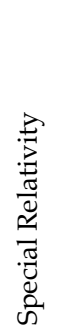 & 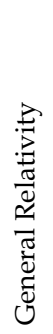 & 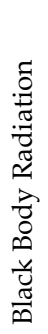 & 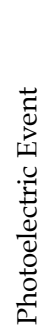 & 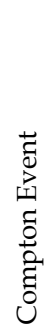 & 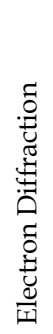 & 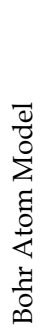 & 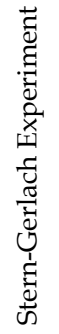 & 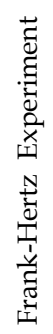 & 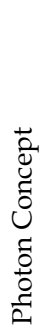 & 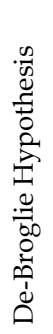 & 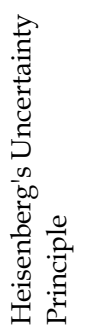 & 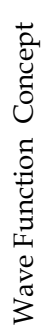 & 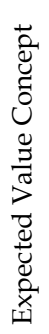 & 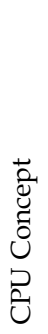 & 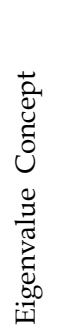 & 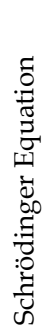 & 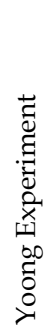 & 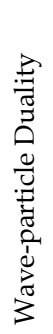 & 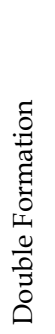 & 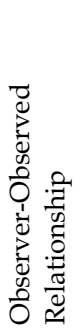 & 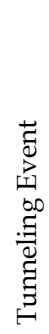 \\
\hline \multirow{2}{*}{ Interesting } & $\% 7$ & $\%$ & $\%$ & $\%$ & $\%$ & $\%$ & $\%$ & $\% 5$ & $\%$ & $\%$ & $\%$ & $\%$ & $\%$ & $\%$ & $\%$ & $\%$ & $\%$ & $\%$ & $\%$ & $\%$ & $\%$ & $\%$ \\
\hline & 9 & 70 & 76 & 74 & 71 & 56 & 62 & 5 & 55 & 80 & 73 & 77 & 60 & 58 & 53 & 58 & 68 & 65 & 77 & 67 & 57 & 74 \\
\hline \multirow{2}{*}{ Concerning } & $\% 5$ & $\%$ & $\%$ & $\%$ & $\%$ & $\%$ & $\%$ & $\% 4$ & $\%$ & $\%$ & $\%$ & $\%$ & $\%$ & $\%$ & $\%$ & $\%$ & $\%$ & $\%$ & $\%$ & $\%$ & $\%$ & $\%$ \\
\hline & 7 & 49 & 49 & 33 & 41 & 37 & 32 & 9 & 34 & 38 & 38 & 55 & 50 & 56 & 56 & 60 & 55 & 43 & 50 & 43 & 40 & 67 \\
\hline Abstract & $\% 8$ & $\%$ & $\%$ & $\%$ & $\%$ & $\%$ & $\%$ & $\% 5$ & $\%$ & $\%$ & $\%$ & $\%$ & $\%$ & $\%$ & $\%$ & $\%$ & $\%$ & $\%$ & $\%$ & $\%$ & $\%$ & $\%$ \\
\hline Causes & $\% 6$ & $\%$ & $\%$ & $\%$ & $\%$ & $\%$ & $\%$ & $\% 6$ & $\%$ & $\%$ & $\%$ & $\%$ & $\%$ & $\%$ & $\%$ & $\%$ & $\%$ & $\%$ & $\%$ & $\%$ & $\%$ & $\%$ \\
\hline Preconceptions & 9 & 59 & 59 & 41 & 46 & 55 & 37 & 0 & 56 & 46 & 50 & 65 & 60 & 56 & 57 & 63 & 71 & 52 & 57 & 55 & 59 & 71 \\
\hline \multirow{2}{*}{ Alienates } & $\% 4$ & $\%$ & $\%$ & $\%$ & $\%$ & $\%$ & $\%$ & $\% 5$ & $\%$ & $\%$ & $\%$ & $\%$ & $\%$ & $\%$ & $\%$ & $\%$ & $\%$ & $\%$ & $\%$ & $\%$ & $\%$ & $\%$ \\
\hline & 8 & 57 & 46 & 29 & 38 & 49 & 38 & 3 & 50 & 40 & 47 & 51 & 56 & 60 & 60 & 63 & 58 & 47 & 54 & 55 & 59 & 64 \\
\hline \multirow{2}{*}{$\begin{array}{l}\text { Contains } \\
\text { Conceptual } \\
\text { Difficulty }\end{array}$} & $\% 6$ & $\%$ & $\%$ & $\%$ & $\%$ & $\%$ & $\%$ & $\% 5$ & $\%$ & $\%$ & $\%$ & $\%$ & $\%$ & $\%$ & $\%$ & $\%$ & $\%$ & $\%$ & $\%$ & $\%$ & $\%$ & $\%$ \\
\hline & 1 & 59 & 57 & 44 & 48 & 53 & 42 & 7 & 60 & 50 & 54 & 61 & 63 & 62 & 63 & 66 & 68 & 58 & 66 & 64 & 61 & 70 \\
\hline \multirow{2}{*}{$\begin{array}{l}\text { Includes } \\
\text { Mathematical } \\
\text { Difficulty }\end{array}$} & $\% 5$ & $\%$ & $\%$ & $\%$ & $\%$ & $\%$ & $\%$ & $\% 6$ & $\%$ & $\%$ & $\%$ & $\%$ & $\%$ & $\%$ & $\%$ & $\%$ & $\%$ & $\%$ & $\%$ & $\%$ & $\%$ & $\%$ \\
\hline & 9 & 59 & 47 & 55 & 58 & 57 & 49 & 7 & 55 & 54 & 59 & 60 & 72 & 70 & 70 & 62 & 73 & 59 & 71 & 62 & 62 & 77 \\
\hline \multirow{2}{*}{$\begin{array}{l}\text { It is Difficult to } \\
\text { Visualize }\end{array}$} & $\% 7$ & $\%$ & $\%$ & $\%$ & $\%$ & $\%$ & $\%$ & $\% 6$ & $\%$ & $\%$ & $\%$ & $\%$ & $\%$ & $\%$ & $\%$ & $\%$ & $\%$ & $\%$ & $\%$ & $\%$ & $\%$ & $\%$ \\
\hline & 8 & 79 & 67 & 56 & 66 & 67 & 58 & 0 & 61 & 69 & 68 & 72 & 71 & 73 & 78 & 71 & 75 & 70 & 72 & 68 & 70 & 80 \\
\hline
\end{tabular}

Considering the Table 2, it can be said that most of the students have negative perceptions. On the other hand, the percentage of the construct of "interesting" has received more than $50 \%$ for all the elements, which means that the students are interested in modern physics, but they have negative perceptions due to a variety of reasons. 
Afterwards, individual interviews were conducted with 10 students, who have higher negative perception scores and accepted to be included in these interviews, after performing the RGT score analyses of 123 participants. The scoring was performed on 7 constructs. The negative perception scores of the students ranged from 770 to 134 . After the scores of the students were sorted from highest to lowest score, ten individuals with highest scores were invited to the interview. The scores of these students were $542,528,484,689,607,486,597,670,502$, and 521 , respectively.

The Findings Obtained from Individual Interviews. The participants were asked by 7 basic questions with 4 descriptive categories as semi-structured and the sub-categories have been created. The answers given by the participants were subjected to descriptive analysis followed by the content analysis. Tables were used in order to present the codes of each question by creating codes to facilitate access to sub-categories. The meanings and frequencies of use of the codes regarding the perception of concern are given in Table 3.

Table 3. The Codes Created for the Perception of Concern, its Meanings and Frequency of Use

\begin{tabular}{|c|c|c|c|c|c|}
\hline \multirow{11}{*}{ 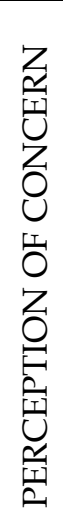 } & Descriptive Categories & No & Code & Definition of the Code & $\mathrm{f}$ \\
\hline & \multirow{2}{*}{ The Effect of Instructors } & 1 & Field & Being Professional in the Field & 3 \\
\hline & & 2 & Method & One type of teaching method & 7 \\
\hline & \multirow{3}{*}{$\begin{array}{l}\text { The effect of in class } \\
\text { activities }\end{array}$} & 3 & Visualization & Using visualizations & 6 \\
\hline & & 4 & Laboratory & Laboratory use & 7 \\
\hline & & 5 & Daily Life & Establishing relations with daily life & 3 \\
\hline & \multirow[t]{3}{*}{ The effect of curriculum } & 6 & Semester & The small number of Semesters & \\
\hline & & 7 & Stationarity & Unchanged & 2 \\
\hline & & 8 & Level & Student Level & 2 \\
\hline & \multirow[t]{3}{*}{ The effect of textbooks } & 9 & Visualization & port & 3 \\
\hline & & 10 & Language & Translat & 3 \\
\hline & & 11 & Content & Mathematical content & 2 \\
\hline
\end{tabular}

The reasons why participants approach modern physics with concern are as follows: inadequate instructors in their field, the use of one type of teaching methods, insufficient use of visualization within the course, insufficient use of laboratories and not establishing the relationship between modern physics and daily life. In addition, insufficient numbers of semesters for the modern physics curriculum, using the same curriculum continuously and not addressing the levels of the students are the other reasons resulting in concern perceptions to emerge. Furthermore, according to participants, the textbooks do not have much space for visualization, there are some translation problems and they have intense mathematical content, which also result in perception of concern in the students.

In Table 4, the codes obtained related to perception of abstract and their frequencies are given. The reason why perception of abstract are observed in the participants are as follows: Mediocrity of the teaching staff in teaching methods, insufficient use of the samples and not being able to establish relationship between modern physics concepts and daily life. In addition to these, some insufficiencies in class activities such as not holding peer discussions, insufficient amount of visualizations and insufficient use of the laboratories result in the perception of abstract in the students. The participants of the study have stated that the subjects in the curriculum should be sorted from easy to difficult and it should support the project based teaching to minimize these perceptions. Considering the textbooks, insufficient amount of visualizations and intense mathematical content have resulted in perception of abstract in the participants. 
Table 4. The Codes Created for Perception of Abstract, Their Meanings and Frequencies of Use

\begin{tabular}{|c|c|c|c|c|c|}
\hline \multirow{11}{*}{ 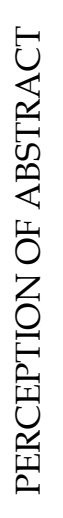 } & Descriptive Categories & No & Code & Definition of the Code & $\mathrm{f}$ \\
\hline & \multirow[t]{3}{*}{ The Effect of Instructors } & 1 & Method & One type of teaching method & 4 \\
\hline & & 2 & Sampling & Using sampling & 6 \\
\hline & & 3 & Daily Life & $\begin{array}{l}\text { Establishing relationship with } \\
\text { daily life }\end{array}$ & 2 \\
\hline & \multirow{3}{*}{$\begin{array}{l}\text { The effect of in class } \\
\text { activities }\end{array}$} & 4 & Peer & Peer support & 3 \\
\hline & & 5 & Visualization & Using visualization & 3 \\
\hline & & 6 & Laboratory & Use of laboratory & 7 \\
\hline & \multirow[t]{2}{*}{ The effect of curriculum } & 7 & Easy to Dif. & Teaching way & 2 \\
\hline & & 8 & Project & Project based curriculum & 2 \\
\hline & \multirow[t]{2}{*}{ The effect of textbooks } & 9 & Visualization & Supporting with visualization & 4 \\
\hline & & 10 & Content & Intense mathematical content & 4 \\
\hline
\end{tabular}

The codes and their frequencies, which were created to see why the participants approach modern physics contents with preconception, are given in Table 5.

Table 5. The Codes Created for Perception of Preconception, Their Meanings and Frequencies of Use

\begin{tabular}{|c|c|c|c|c|c|}
\hline \multirow{10}{*}{ 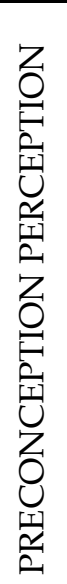 } & $\begin{array}{l}\text { Descriptive } \\
\text { Categories }\end{array}$ & No & Code & Definition of the Code & $\mathrm{f}$ \\
\hline & The Effect & 1 & Attitude & The attitudes of instructors regarding the class & 7 \\
\hline & Instructors & 2 & Method & Mediocrity in teaching methods & 4 \\
\hline & & 3 & Field & Dominance in the field & 3 \\
\hline & The effect of in class & 4 & Laboratory & Using the laboratory & 6 \\
\hline & activities & 5 & Visualizatio & Pointing the visualization out & 5 \\
\hline & & 6 & $\begin{array}{l}\mathrm{n} \\
\text { Peer }\end{array}$ & Having peer support & 3 \\
\hline & The effect & 7 & Easy & Level of the student & 4 \\
\hline & curriculum & 8 & $\begin{array}{l}\text { Difficult } \\
\text { Semester }\end{array}$ & Insufficient number of semesters & \\
\hline & $\begin{array}{l}\text { The effect } \\
\text { textbooks }\end{array}$ & 9 & Content & Intense mathematical content & 6 \\
\hline
\end{tabular}

The reasons why participants approach modern physics and its concepts with preconceptions are as follows; the attitudes of the teaching staff towards the course, the problems encountered in their teaching methods and the necessity of being specialized in the field of modern physics. In addition to these, some insufficiencies peer support, insufficient amount of visualizations and insufficient use of the laboratories result in preconceptions. Furthermore, insufficient number of semesters and the problems encountered while preparing the curriculum have supported the findings stating that they caused preconception. According to participants, especially the intense mathematical content has caused preconceptions in students.

The reasons why the participants feel themselves as alienated are identified by analyzing the codes given in Table 6. The reasons why the participants feel themselves as alienated to modern physics are as follows; not well equipped teaching staff in the field, insufficient amount of peer support during the class, insufficient level of laboratory use and the lack of the relationship between students and instructors. Especially the sense of loss arising due to translation of the books and intense mathematical content of the textbooks were stated as the reasons causing alienation of the students to modern physics and its contents. 
Table 6. The Codes Created for Perception of Alienation, Their Meanings and Frequencies of Use

\begin{tabular}{|c|c|c|c|c|c|}
\hline \multirow{9}{*}{ 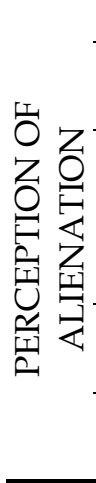 } & Descriptive Categories & No & Code & Definition of the Code & $\mathrm{f}$ \\
\hline & The Effect of Instructors & 1 & Method & Diversity of Teaching Methods & 5 \\
\hline & & 2 & Field & Dominance in the Field & 4 \\
\hline & The effect of in class & 3 & Peer & Having Peer Support & 4 \\
\hline & activities & 4 & Laboratory & Using the Laboratories & 4 \\
\hline & & 5 & $\begin{array}{l}\text { Communicatio } \\
\mathrm{n}\end{array}$ & Communication with the Student & 5 \\
\hline & The effect of curriculum & 6 & $\begin{array}{l}\text { Easy } \\
\text { Difficult }\end{array}$ & Teaching Way & 6 \\
\hline & The effect of textbooks & 7 & Language & Translation Problems with Textbooks & 5 \\
\hline & & 8 & Content & Intense Mathematical Content & 5 \\
\hline
\end{tabular}

In Table 7 , the codes obtained related to perception of conceptual difficulty and their repetition numbers are given. The reasons for the emergence of conceptual difficulty perception in the participants are as follows; not adapting modern physics to daily life by the instructors, mediocrity in teaching methods, not using the laboratories and insufficient use of visualizations. In addition, it has been seen that not considering the readiness level of the students while preparing the curriculum has caused conceptual difficulty perception. Furthermore, the lack of establishing the relationship between modern physics and daily life and insufficient use of visualizations in the textbooks are some other reasons that cause conceptual difficulties.

Table 7. The Codes Created for Perception of Conceptual Difficulty, Their Meanings and Frequencies

\begin{tabular}{|c|c|c|c|c|c|}
\hline \multirow{9}{*}{ 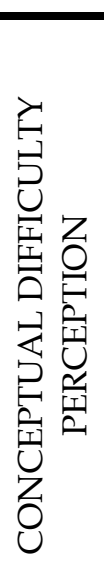 } & $\begin{array}{l}\text { Descriptive } \\
\text { Categories }\end{array}$ & No & Code & Definition of the Code & $\bar{f}$ \\
\hline & The Effect & 1 & Daily Life & Lack of establishing the relationship with daily & 4 \\
\hline & Instructors & 2 & Method & $\begin{array}{l}\text { life } \\
\text { Mediocrity in teaching methods }\end{array}$ & 4 \\
\hline & The effect of in class & 3 & Daily Life & Lack of establishing the relationship with daily & 3 \\
\hline & activities & 4 & Laboratory & life & 5 \\
\hline & & 5 & Visualization & $\begin{array}{l}\text { Laboratory use } \\
\text { Highlighting the visualizations }\end{array}$ & 3 \\
\hline & The effect & 6 & Easy & Teaching way & 3 \\
\hline & curriculum & 7 & $\begin{array}{l}\text { Different } \\
\text { Readiness }\end{array}$ & Considering the readiness levels & 6 \\
\hline & The effect & 8 & Daily Life & Creating the relationship with daily life & 3 \\
\hline & textbooks & 9 & Visualization & Highlighting the visualizations & 6 \\
\hline
\end{tabular}

In Table 8, the codes obtained regarding the perception of mathematical difficulty and their frequencies of use are given. The reasons for the emergence of the mathematical difficulty perception in the participants are as follows; not well equipped teaching staff in the field and the lack of proper teaching staff. In addition, some other reasons, stated by the participants, causing mathematical difficulty perception are choosing subjects requiring intense mathematical equations in the curriculum, not considering the readiness levels of the students, creating the textbooks by formulas only and insufficient use of visualizations.

Table 8. The Codes Created for Perception of Mathematical Difficulty, Their Meanings and Frequencies of Use

\begin{tabular}{|c|c|c|c|c|c|}
\hline \multirow{5}{*}{ 岕焉焉 } & Descriptive Categories & No & Code & Definition of the Code & $\mathrm{f}$ \\
\hline & The Effect & 1 & Field & Dominance in the field & 5 \\
\hline & Instructors & 2 & Equipment & Being well equipped in math & 4 \\
\hline & & 3 & Method & Diversity of teaching methods & 6 \\
\hline & The effect of in class & 4 & Laboratory & Using laboratories & 3 \\
\hline
\end{tabular}




\begin{tabular}{llllll}
\hline activities & 5 & Method & Mediocrity in teaching methods & 7 \\
\hline The effect & of & 6 & Intensity & Subjects with intense mathematical & 5 \\
curriculum & 7 & Readiness & $\begin{array}{l}\text { content } \\
\text { The readiness level of students }\end{array}$ & 3 \\
& & & Ther & 6 \\
\hline The effect of textbooks & 8 & Formula & Intense mathematical formulas & 6 \\
\hline
\end{tabular}

In Table 9, the codes obtained regarding the perception of "visualization is difficult" and their frequencies are given. The reasons for the emergence of the perception of visualization difficulty in the participants are as follows; insufficient amount of the activities conducted by the instructors, inability to create analogies and the lack of activities that may trigger imagination of the students. Considering the classroom activities; insufficient amount of peer support and demonstration experiments are the reasons causing he perception of visualization difficulty. Some other reasons causing the perception of visualization difficulty are as follows; the curriculum which cannot trigger the imagination of the students, incapability of the textbooks in terms of establishing the relationship between modern physics and daily life and the lack of visualizations.

Table 9. The Codes Created for Perception of Visualization Difficulty, Their Meanings and Frequencies of Use

\begin{tabular}{|c|c|c|c|c|c|}
\hline & Descriptive Categories & No & Code & Definition of the Code & $\mathrm{f}$ \\
\hline$\stackrel{5}{2}$ & The Effect of Instructors & 1 & Effectiveness & Including different activities & 3 \\
\hline$\underline{U}$ & & 2 & Analogy & Making analogies & 5 \\
\hline 岁哥 & & 3 & Imagination & $\begin{array}{l}\text { Revealing the imagination of the } \\
\text { student }\end{array}$ & 6 \\
\hline Ò & The effect of in class & 4 & Support & Having peer support & 5 \\
\hline$\hat{y}_{1} Z_{0}$ & activities & 5 & $\begin{array}{l}\text { Demonstratio } \\
\mathrm{n}\end{array}$ & Having demo experiments & 4 \\
\hline 采 & The effect of curriculum & 6 & Activation & $\begin{array}{l}\begin{array}{l}\text { Activating the imagination of } \\
\text { students }\end{array} \\
\end{array}$ & 4 \\
\hline$\underset{⿱}{\infty}$ & The effect of textbooks & $\begin{array}{l}7 \\
8\end{array}$ & $\begin{array}{l}\text { Daily Life } \\
\text { Visualization }\end{array}$ & $\begin{array}{l}\text { Establishing the relationship with } \\
\text { daily life }\end{array}$ & $\begin{array}{l}3 \\
5\end{array}$ \\
\hline
\end{tabular}

\section{Results and Recommendations}

The Newtonian paradigm, which was dominant until the 17th century, or deterministic (based on causality) perspective did not allow different ideas regarding events and phenomena in the science world. Especially different ideas in the mass, matter, space and epistemological changes (nature of knowledge) in the tissue of time were not imaginable. In the 19th century, the serious progress achieved in physics has led emergence of a new concept of physics called modern physics and resulted in questioning the current knowledge by the scientific community. In particular, the special and general relativity theories, striking ideas regarding speed and space-time subjects clearly demonstrated that the deterministic paradigm must be dropped out. The indeterministic paradigm (not based on causality) has been revealed with the quantum hypothesis of Max Planck in 1900 and it has been clearly emphasized that the modern physics is the one that should be focused on from that point. This new field of physics has encountered many criticisms during that period, which may be caused by its abstract content. In fact, the ideas presented by modern physics were away from everyday intuitions and very different compared to the ideas of usual physics, which make those criticisms more justifiable. However, even though the idea of applying to modern physics as a source to understand the nature was not commonly accepted, modern physics has taken its place in the world of science. It is not very surprising that the students have negative perceptions regarding this physics which is still approached suspiciously. The important thing is realizing these negative perceptions and taking measures in order to avoid these perceptions. 
Therefore, the aim of this study is presenting the negative perception of undergraduate students, who take physics courses, towards modern physics and the causes of these negative perceptions. For this purpose, focus group interviews, individual interviews and repertory grid technique were conducted. The focus group interviews were performed with three different groups consisting 12 students each. The data obtained from these interviews were used to create the repertory grids. The repertory grid technique was conducted with 123 students. The repertory grid technique is a qualitative data collection method. However, it has been used to generate quantitative data in this study. The general data were obtained from the repertory grid and the students were identified to conduct individual interviews. The most important findings of the study were obtained from individual interviews. The causes of negative perceptions have been identified from individual interviews conducted with ten students.

According to data obtained from the focus group interviews used to collect data and the repertory grid technique, modern physics create concerns in the students, seems abstract to them and this causes them to have preconceptions regarding modern physics. In addition, the students feel themselves as alienated to modern physics and have negative perceptions as it has mathematical and conceptual difficulties. According to Shankar (1994) and McMurry (1994), students must have a good knowledge of mathematics to not to encounter problems in terms of mathematical operations while dealing with modern physics problems. In parallel with result of conceptual difficulty, McDermott and Redish (1999) have stated that the conceptual content of modern physics is less understood by the students than expected.

In the final stage of the study, semi-structured individual interviews were conducted to find the causes of negative perceptions. According to results obtained from these interviews, the causes of negative perceptions of the students towards modern physics can be listed as follows:

- $\quad$ Student thinks that the instructor is not mastered in the subject

- $\quad$ The use of a single type teaching method by the instructor

- Insufficient visualization regarding the course

- $\quad$ Low efficiency of laboratory activities

- $\quad$ Failure to establish the relationship between the subject and everyday life in the course

- The excessive number of the subjects in the course

- Inappropriate subjects for the levels of students in the curriculum

- The lack of clear translation of textbooks

- $\quad$ Redundancy and complexity of mathematical operations

- $\quad$ The instructors do not take the readiness level of students into account

- Failure to establish analogies by the instructors

Similar to these findings, McDermott (1991) has stated that there is an inconsistency between what instructors teach and what students understand. In traditional teaching methods, many instructors were unaware of what kind of perceptions the students used to have during the physics education. Similar to the findings of the teaching method, according to Didis (2012), the presentation of modern physics with traditional methods would not give effective results due to its abstract content and different mathematical structure compared to the classical physics.

In this study, it has been concluded that the negative perceptions of the students towards modern physics should be identified, more pedagogical work should be done to avoid these perceptions and all the opportunities required by the era should be provided for the students. In particular, the instructors must be well-equipped pedagogically, classroom activities should be appropriate to modern physics contents, textbooks should be up to date and the curriculum of physics should be reorganized in order to minimize the negative perceptions of the students towards modern physics. In this regard, the findings of our study present useful ideas for realizing the negative perceptions of students towards modern physics and its contents. 


\section{References}

Akarsu, B. (2011). Evaluating college students' conceptual knowledge of modern physics: test of understanding on concepts of modern physics. European Journal of Physics Education, 2(1), 32-37.

Bilal, E. \& Erol, M. (2007). Student understanding of some quantum physical concepts: wave function, Schrödinger's wave equation and wave-particle duality. Proceedings of the Sixth International Conference of the Balkan Physical Union. Istanbul, Turkey (pp. 479-480).

Didis, N. (2012). Investigation of undergraduate students' mental models about the quantization of physical observables (Unpublished doctoral dissertation). Middle East Technical University, Ankara, Turkey.

Euler, M., Hanselmann, M., Müller, A., \& Zollman, D. (1999). Students' views of models and concepts in modern physics. Proceedings of the National Association for Research in Science Teaching. New Orleans, USA (p. 15-19).

Halloun, I. A. \& Hestenes, D. (1985a). The initial knowledge state of college physics sdudents. American Journal of Physics, 53(11), 1043-1055.

Halloun, I.A. \& Hestenes, D. (1985b). Common sense concepts about motion. American Journal of Physics, 53(11),1156-1165.

Kelly, G.A. (1955). The psychology of personal constructs, New York, NY: WW Norton \& Company, Inc.

Mannila, K., Koponen, I. T., \& Niskanen, J. A. (2002). Building a picture of students' conceptions of wave-and particle-like properties of quantum entities. European Journal of Physics, 23(1), 45.

McDermott, L. C. (1991). Millikan Lecture 1990: What we teach and what is learned-Closing the gap. American Journal of Physics, 59(4), 301-315.

McDermott, L. C., \& Redish, E. F. (1999). Resource letter: PER-1: Physics education research. American journal of physics, 67(9), 755-767.

McMillan, J.H., \& Schumacher, S. (2010). Research in education: Evidence based enquiry(7th ed.). Boston, MA: Pearson

McMurry, M. S. (1994). Quantum Mechanics. Wokingham, CA: Addison Wesley Longman.

Ozcan, O. (2011). Pre-service physics teachers' problem solving approaches in special theory of relativity. Hacettepe. University Journal of Education,40(40).

Patton, M. Q. (2005). Qualitative research. London: John Wiley \& Sons, Ltd.

Prosser, M., Walker, P., \& Millar, R. (1996). Differences in students' perceptions of learning physics. Physics Education, $31(1), 43$.

Redish, E.F. \& Steinberg, R. N. (1999). Teaching physics Figuring out What Works. Physics Today, 52, 24-30.

Selcuk, G. S., Caliskan, S., \& Ajangiz, R. (2009). Student understanding of some quantum physical concepts. Latin-American Journal of Physics Education, 3(2), 2.

Shankar, R. (1994). Principles of Quantum Mechanics, (2nd ed.). New York, NY: Plenum Press Trowbridge, D. E., \& McDermott, L. C. (1980). Investigation of student understanding of the concept of velocity in one dimension. American journal of Physics, 48(12), 1020-1028.

Turgut, U., Gurbuz, F., Salar, R., \& Toman, U. (2013). The viewpoints of physics teacher candidates towards the concepts in special theory of relativity and their evaluation designs. International Journal of Academic Research, 5(4).

Viennot, L., \& Rozier, S. (1994). Pedagogical outcomes of research in science education: Examples in mechanics and thermodynamics. In P. J. Fensham, R. F. Gunstone, \& R. T.

White (Ed.), The content of science: A constructivist approach to its teaching and learning. London: Falmer Press. 